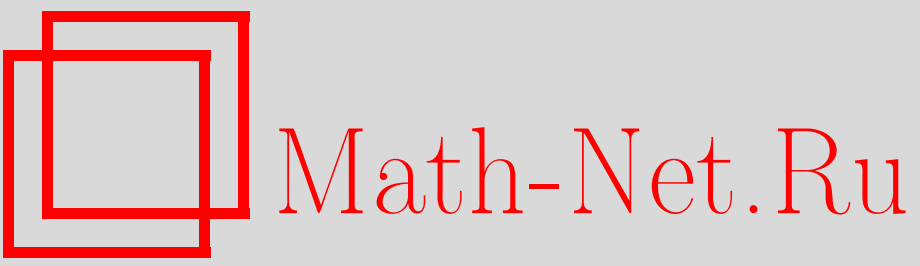

С. Л. Яковлев, Памяти Станислава Петровича Меркурьева, ТМФ, 1996, том 107, номер 3, 353-356

DOI: https://doi.org/10.4213/tmf1161

Использование Общероссийского математического портала Math-Net.Ru подразумевает, что вы прочитали и согласны с пользовательским соглашением

http://www.mathnet.ru/rus/agreement

Параметры загрузки:

IP : 52.90 .164 .192

26 апреля 2023 г., 12:43:44

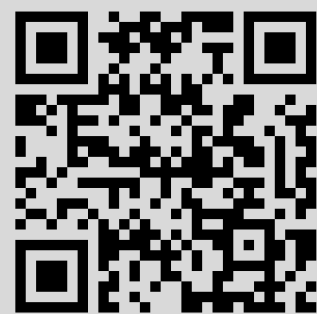




\section{Памяти \\ Станислава Петровича Меркурьева}

$(28.04 .1945-18.05 .1993)$

18 мая 1996 г. исполнилось три года со дня смерти действительного члена Российской академии наук, ректора Санкт-Петербургского университета, заведующего кафедрой вычислительной физики физического факультета, доктора физико-математических наук, профессора Станислава Петровича Меркурьева. За свою короткую, чуть более 48 лет, жизнь он внес большой вклад в решение многих проблем математической и теоретической физики. Классическими стали его исследования по квантовой теории систем нескольких частиц. В числе основных результатов - спектральные тождества для трехчастичных матриц рассеяния и их приложения к вириальным разложениям статистической физики, изучение асимптотических свойств волновых функций трехчастичных систем в конфигурационном пространстве и разработка на их основе вариационных принципов для амплитуд трехчастичных реакций, решение математических и вычислительных проблем квантовой теории рассеяния для систем трех заряженных частиш, 
создание нового подхода к решению проблемы $N$ тел в квантовой механике на основе дифференциальных уравнений в конфигурационном пространстве, разработка методов статистического моделирования для квантовых систем нескольких частиц, формулировка адиабатических разложений в терминах гильбертовых расслоений,исследования по физике малонуклонных систем и структуре адронов, атомной и мезоатомной физике.

С.П.Меркурьев родился 28 апреля 1945 г. в г. Кустанае в семье военного летчика. Точные науки привлекали его внимание уже в школьные годы, и после окончания школы он поступает на физический факультет Ленинградского университета. Здесь под влиянием таких выдающихся представителей ленинградской школы математической физики, как В.И.Смирнов, О.А.Ладыженская, Л.Д.Фаддеев, М.Ш.Бирман, В.С.Буслаев формируются научные интересы ученого - математические методы квантовой физики. В 1968 г. С.П.Меркурьев поступает в аспирантуру, где под руководством В.С.Буслаева приступает к исследованиям по теории квантовых систем трех частиц. Эта область в те годы привлекала пристальное внимание теоретиков прежде всего благодаря доказательству Л.Д.Фаддеевым в 1963 г. теорем существования и единственности решения спектральной задачи для трехчастичных гамильтонианов. Основываясь на этих результатах, С.П.Меркурьев доказывает гипотезу Бете и Уленбека о возможности представления третьего вириального коэффициента для статистик Больцмана, Бозе-Эйнштейна и Ферми-Дирака через трехчастичную матрицу рассеяния. Полученные им представления для третьего вириального коэффициента и связанного с ним третьего группового интеграла исправляют ошибочные формулы других авторов, предполагавших, что асимптотика трехчастичной волновой функции в конфигурационном пространстве, как и в случае двухчастичной волновой функции, представляется суммой плоской и сферической волн. Исследование координатной асимптотики волновых функций для системы трех частиц привело С.П.Меркурьева к обнаружению медленно убывающих слагаемых, отвечающих процессам последовательных разделенных столкновений частиц. Цикл этих работ составил основу кандидатской диссертации “Третий вириальный коэффициент, матрица рассеяния и координатная асимптотика волновой функции для системы трех частищ", которую С.П.Меркурьев зашитил в 1971 г.

Продолжая исследования, С.П.Меркурьев находит координатные асимптотики собственных функций дискретного спектра для трехчастичных гамильтонианов, разрабатывает вариационные принципы для нахождения амплитуд трехчастичных реакций и, наконец, создает в 1975 г. (совместно с К.Жинью (C.Gignoux) и А.Лаверном (A.Laverne)) новую формулировку квантовой теории рассеяния для систем трех частищ, основанную на дифференциальных уравнениях Фаддеева в конфигурационном пространстве. Новый подход дал возможность разработать эффективные алгоритмы численного решения и позволил его авторам впервые рассчитать характеристики упругого рассеяния и развала в нейтрон-дейтронном рассеянии на основе безмодельного решения проблемы трех тел. Этими исследованиями было положено начало применению в малонуклонной физике одного из самых эффективных методов численного решения задачи трех тел - метода дифференциальных уравнений Фаддеева в координатном пространствe.

Применение оригинальных интегральных и дифференциальных уравнений Фаддеева в ядерной и атомной физике было ограничено невозможностью изучения на их ос- 
нове систем с дальнодействуюшими кулоновскими взаимодействиями между частицами и систем, в которых взаимодействие описывается граничными условиями на волновую функцию. С.П.Меркурьев берется за решение этих проблем. В 1978 г. он создает теорию рассеяния для трех заряженных частиц и защищает докторскую диссертацию "Квантовая теория рассеяния для системы трех заряженных частиц". В этой работе доказано сушествование волновых операторов, исследованы строение резольвенты оператора энергии для системы трех заряженных частиц и координатные асимптотики волновых функций, доказана теорема полноты, введены модифицированные дифференциальные уравнения Фаддеева и для них сформулированы граничные задачи , отвечающие физическим волновым функциям. Эти результаты создали математическую базу для многочисленных приложений модифицированных уравнений Фаддеева к расчетам рассеяния в трехчастичных системах с участием заряженных частиц, выполненных С.П.Меркурьевым с учениками.

Накопленный опыт решения математических проблем квантовой задачи трех тел позволил С.П.Меркурьеву (совместно с С.Л.Яковлевым) обобщить метод дифференциальных уравнений Фаддеева на случай систем произвольного числа частиц, исследовать структуру главных сингулярностей резольвенты оператора энергии системы $N$ тел и на ее основе описать координатные асимптотики волновых функций рассеяния в системах взаимодействующих кластеров. Это привело к созданию дифференциальной формулировки задачи рассеяния для системы $N$ тел, обладающей всеми достоинствами трехчастичных уравнений Фаддеева. На основе такой формулировки в 1984 г. были выполнены первые безмодельные расчеты четырехнуклонных систем (совместно с С.Л.Яковлевым и К.Жинью).

1980-1993 годы - годы напряженной работы С.П.Меркурьева как над решением математических проблем квантовой механики, так и над приложениями теории к конкретным задачам ядерной и атомной физики. Совместно с А.К.Мотовиловым создана теория рассеяния для трехчастичных систем с сингулярными взаимодействиями, задаваемыми граничными условиями. Совместно с А.А.Квицинским исследованы околопороговые сингулярности амплитуд рассеяния для систем нескольких частищ с медленно убьвающими потенциалами. Совместно с А.А.Квицинским и В.В.Кострыкиным разработано представление полного момента для трехчастичных уравнений Фаддеева, построена математическая теория эффекта Штарка. Совместно с Ю.А.Купериным, А.А.Квицинским, В.В.Кострыкиным и Ю.Б.Мельниковым дано математическое обоснование адиабатических представлений трехчастичных волновых функций, порождаемых различными координатными редукциями трехчастичного гамильтониана. Совместно с С.А.Немнюгиным развивались методы статистического моделирования для расчета характеристик связанных состояний малочастичных квантовых систем. Совместно с А.А.Квицинским, Ю.А.Купериным, Д.М.Латыповым, С.А.Немнюгиным, Е.А.Яревским вьполнен огромный объем работ по численному решению задач малонуклонной физики, физики адронов, мезоатомной физики. Это годы создания научной школы, к которой принадлежат доктора физико-математических наук А.А.Квищинский, Ю.А.Куперин, кандидаты физико-математических наук С.Л.Яковлев, В.В.Кострыкин, Д.М.Латыпов, Ю.Б.Мельников, А.К.Мотовилов, С.А.Немнюгин, И.Н.Филихин, Е.А.Яревский. 
В то же самое время последние тринадцать лет жизни - годы большой научно-организаторской работы. В 1980 г. тридцатипятилетний доктор наук, профессор С.П.Меркурьев избирается деканом физического факультета ЛГУ. В 1984 г. он организует первую в СССР кафедру вычислительной физики. В 1985 г. Ученый совет ЛГУ избирает С.П.Меркурьева ректором университета. Заслуги С.П.Меркурьева в обновлении университетского образования отмечены избранием его в руководство Конференции ректоров университетов Европы, а также вице-президентом Евро-Азиатской ассоциации университетов. В 1987 г. С.П.Меркурьев избирается членом-корреспондентом Академии наук СССР, а в 1991 г. - действительным членом Российской академии наук. Он был иностранным членом Академии искусств и наук г. Барселона, почетным доктором ряда ведущих зарубежных университетов.

В последние годы в сферу научных интересов С.П.Меркурьева попадают математическое моделирование социально-экономических систем, экология, проблемы управления наукой и высшим образованием и другие.

Внезапная смерть прервала многогранную деятельность Станислава Петровича, однако его научные идеи развиваются и продолжают воплошаться в жизнь его учениками.

С.Л.Яковлев 